\title{
Peripheral refraction and image blur in four meridians in emmetropes and myopes
}

This article was published in the following Dove Press journal: Clinical Ophthalmology

\author{
Jie Shen' \\ Frank Spors' \\ Donald Egan ${ }^{2}$ \\ Chunming Liu $^{3}$ \\ 'Western University of Health \\ Sciences, College of Optometry, \\ Pomona, CA, ${ }^{2}$ University of Pikeville \\ Kentucky College of Optometry, \\ Pikeville, KY, ${ }^{3}$ Pacific University \\ College of Optometry, Forest Grove, \\ OR, USA
}

Introduction: The peripheral refractive error of the human eye has been hypothesized to be a major stimulus for the development of its central refractive error.

Aim: The purpose of this study was to investigate the changes in the peripheral refractive error across horizontal, vertical and two diagonal meridians in emmetropic and low, moderate and high myopic adults.

Subjects and methods: Thirty-four adult subjects were recruited and aberration was measured using a modified commercial aberrometer. We then computed the refractive error in power vector notation from second-order Zernike terms. Statistical analysis was performed to evaluate the statistical differences in refractive error profiles between the subject groups and across all measured visual field meridians.

Results: Small amounts of relative myopic shift were observed in emmetropic and low myopic subjects. However, moderate and high myopic subjects exhibited a relative hyperopic shift in all four meridians. Astigmatism $\mathrm{J}_{0}$ and $\mathrm{J}_{45}$ had quadratic or linear changes dependent on the visual field meridians. Peripheral Sphero-Cylindrical Retinal Image Blur increased in emmetropic eyes in most of the measured visual fields.

Conclusion: The findings indicate an overall emmetropic or slightly relative myopic periphery (spherical or oblate retinal shape) formed in emmetropes and low myopes, while moderate and high myopes form relative hyperopic periphery (prolate, or less oblate, retinal shape). In general, human emmetropic eyes demonstrate higher amount of peripheral retinal image blur.

Keywords: off-axis, refractive error, aberrometry, myopia, image quality

\section{Introduction}

When simply viewed as an optical instrument, the human eye is imperfect, with defocus, astigmatism and higher order aberrations being common. These optical deficiencies exist for both central and peripheral vision. Central vision has been studied for many years, and clinicians devote themselves to correct them. The importance and potential correction of peripheral refractive errors is not well understood. They influence the peripheral retinal image quality (IQ) and, therefore, also influence peripheral vision. Peripheral vision is important for motion and pattern detection. ${ }^{1,2}$ Peripheral IQ is highly relevant for fundus imaging. ${ }^{3}$ Interest in studying the off-axis optical performance and retinal IQ of the human eye has increased dramatically in recent years because some studies suggest that ocular off-axis aberrations influence the development of a central refractive error. ${ }^{4-8}$ Experiments conducted on different animal species, including primates, demonstrated that eye growth is controlled by local retinal mechanisms. ${ }^{9-11}$ Some studies suggest that peripheral aberrations, including defocus and astigmatism, may influence the foveal refractive development in human eyes as well. ${ }^{12-15}$ During regular human visual development, eye growth tends to minimize
Correspondence: Jie Shen

Western University of Health Sciences, College of Optometry, 309 E 2nd Street, Pomona, CA, USA

Tel +l 9097063878

Email jshen@westernu.edu
Clinical Ophthalmology 2018:12 345-358

(c) (1) (8) ( 2018 Shen et al. This work is published and licensed by Dove Medical Press Limited. The full terms of this license are available at hitps://www.dovepress.com/terms.ph cc. hereby accept the Terms. Non-commercial uses of the work are permitted without any further permission from Dove Medical Press Limited, provided the work is properly attributed. For peminsion for commercial use of this work, please see paragraphs 4.2 and 5 of our Terms (https://www.dovepress.com/terms.php). 
the image blur on the most part of the retina, known as the "grow to clarity" model. ${ }^{16}$

Most studies in the field focused on evaluating peripheral refraction and optical aberrations along the horizontal visual field:3,17-20 some also measured refractive changes along the vertical meridian. ${ }^{21,22}$ These studies demonstrated that refractive error (curvature of field and astigmatism) and IQ differ significantly with retinal eccentricity. Most studies agree that, in the horizontal visual field, hyperopic and emmetropic (Em.) eyes have peripheral refractive errors which are myopic relative to the fovea. In contrast, myopic eyes have less myopia in the peripheral visual field than in the fovea. However, there is controversy regarding the generality of this finding for the vertical meridian. ${ }^{21,22}$

Based on the theory that ocular growth is controlled by local retinal mechanisms, ${ }^{9}$ more comprehensive evaluations of peripheral refraction and IQ changes in the full visual field, rather than just horizontal or vertical meridian, are necessary. The purpose of this study was to investigate the changes in peripheral refractive error across horizontal, vertical and two diagonal meridians across the visual field in Em. and low, moderate and high myopic (LM, MM and $\mathrm{HM}$, respectively) adults.

\section{Subjects and methods}

This study followed the tenets of the Declaration of Helsinki and was approved by the Western University of Health Sciences Institutional Review Board before study commencement. All subjects gave their written consent to participate in this study after being informed about the nature and possible consequences of study participation.

A total of 34 adult subjects participated in this study. The participants were 8 emmetropes (mean spherical equivalent refraction between -0.50 and $+0.50 \mathrm{D}$, age range 19-33 years) and 26 myopes (between -0.70 and $-8.60 \mathrm{D}$, age range 19-31 years). We sought $80 \%$ power to detect a $0.25 \mathrm{D}$ difference in spherical equivalent (SE) between the peripheral and central visual fields with a significance level of 0.05 (two tailed). Assuming the same mean SE values and $\mathrm{SD}$ as reported from the literature, ${ }^{23,24}$ a sample size of 31 ( 7 emmetropes, and 9 low, 8 moderate and 7 high myopes) was calculated. Astigmatism in all subjects was $<1.50 \mathrm{D}$. We computed the sphero-cylindrical refractive error in power vector notation ( $\mathrm{M}, \mathrm{J}_{0}, \mathrm{~J}_{45}$ ) from second-order Zernike terms. Myopic patients were subgrouped into low myopes (from -0.75 to $-3.00 \mathrm{D}$ ), moderate myopes (from -3.25 to $-6.00 \mathrm{D})$ and high myopes $(>-6.00 \mathrm{D})$. To preserve a natural viewing condition, no cycloplegic or mydriatic agents were applied. The participants reported no ocular pathology or ocular surgery history. To avoid confounding factors, we measured only their right eyes.

We obtained refractive measurements with a commercial Shack-Hartmann wavefront aberrometer (Complete Ophthalmic Analysis System [COAS]; AMO Wavefront Sciences, Inc., Albuquerque, New Mexico) on the participants' right eyes in a dark room to ensure the largest natural pupil sizes. We chose this instrument, rather than a conventional autorefractor, because it uses a Shack-Hartmann wavefront sensor to obtain a detailed wavefront analysis of the entire entrance pupil, rather than the central limited pupil size analyzed in the autorefractor. This allowed us to obtain data even when the pupil appeared elliptical when viewed obliquely during the measurement of peripheral refractive errors. According to the manufacturer's specifications, the COAS can measure spherical refractive errors within the range of -15.00 to $+7.00 \mathrm{D}$ with an accuracy of $\pm 0.10 \mathrm{D}$ and a repeatability of $\pm 0.05 \mathrm{D}$. We aligned the participants with the COAS aberrometer using its internal cameras. The cameras are coaxial with the wavefront sensor and are focused using the virtual Purkinje images of light-emitting diodes on the face of the instrument. The COAS aberrometer is a robust and reliable instrument for measuring both lower and higher order aberrations in the central visual field ${ }^{25-27}$ and for measuring peripheral ocular aberrations for elliptical entrance pupils that occur in the off-axis viewing condition. ${ }^{28}$ We modified the COAS wavefront aberrometer to take measurements in $10^{\circ}$ steps out to $\pm 30^{\circ}$ of eccentricity along four visual field meridians, that is, horizontal, vertical and two diagonal meridians (Figure 1).

Maltese cross was used in this study as the fixation target. It was projected onto a screen which was placed $1 \mathrm{~m}$ away from the subjects. The subjects' right eyes were able to see the targets through a beam splitter while keeping the left eye covered. For off-axis measurements, a fixation target projected onto the peripheral visual field was used to elicit eyes' rotation (keeping the head fixed) relative to the aberrometer's measurement axis. Measurements were taken 1 second after a blink to ensure a smooth and stable tear film. For each gaze position, three measurements were taken after realigning the instrument with the measured eye.

The range of eccentricities accessible in human subjects by our instrument is limited to $30^{\circ}$ in both nasal and temporal horizontal visual fields. ${ }^{29}$ We used the same approach in this study to judge the accessibility of the instrument for other visual field meridians (vertical meridian and two diagonal meridians) and obtained Zernike coefficients up to the sixth order. In our previous article, ${ }^{28}$ we demonstrated the validity of using commercial software CLAS-2D to analyze off-axis data. We adopted the same analytical approach in this study: using 


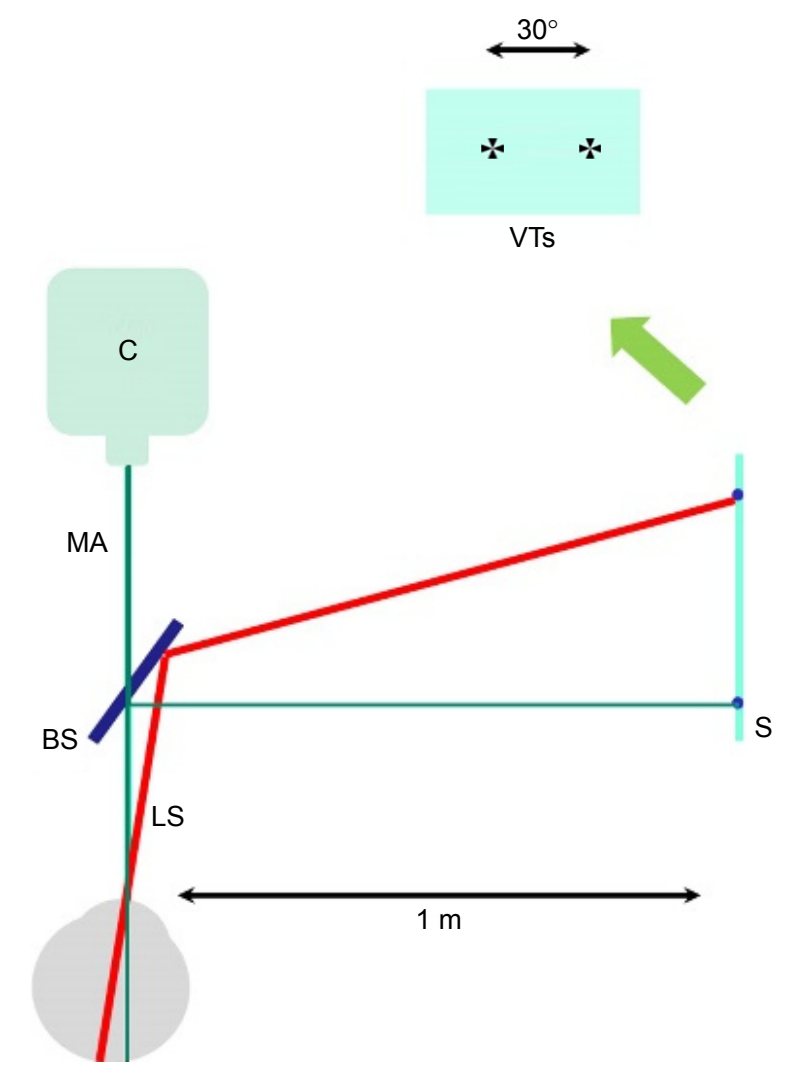

Figure I Experimental setup.

Note: $C$ is the aberrometer.

Abbreviations: BS, beam splitter; LS, line of sight; MA, measurement axis; S, screen; VTs, visual targets.

CLAS-2D software to draw an analysis Zernike circle that is concentric with, and surrounds, the elliptical entrance pupil. Computation of the Zernike coefficients ignores the area between the analysis circle and the elliptical entrance pupil. ${ }^{28}$ The mean \pm SD pupil diameter across all subjects was $6.73 \pm 0.54 \mathrm{~mm}$ (range $5.70-7.75 \mathrm{~mm}$ ) and the largest pupil was $7.75 \mathrm{~mm}$. We, therefore, used a $7.75 \mathrm{~mm}$ circle as a common basis for Zernike analysis of all eyes. We computed the power vector components of the eye's sphero-cylindrical refractive error (M: the SE, $\mathrm{J}_{0}$ : with-the-rule (WTR) and against-the-rule (ATR) astigmatism, $\mathrm{J}_{45}$ : oblique astigmatism with axes at $45^{\circ}$ and $135^{\circ}$ ) using the following equations from second-order Zernike terms. ${ }^{30}$ All results refer to $840 \mathrm{~nm}$ wavelength infrared laser light, which was used in the COAS aberrometer. No correction for ocular chromatic aberration was required for differential results that quantify relative changes.

$$
\begin{aligned}
& \mathrm{M}=\frac{-4 \sqrt{3}}{r^{2}} \mathrm{C}_{2}^{0} \\
& \mathrm{~J}_{0}=\frac{-2 \sqrt{6}}{r^{2}} \mathrm{C}_{2}^{2} \\
& \mathrm{~J}_{45}=\frac{-2 \sqrt{6}}{r^{2}} \mathrm{C}_{2}^{-2}
\end{aligned}
$$

where $\mathrm{C}$ is the Zernike coefficient for defocus $\left(\mathrm{C}_{2}^{0}\right)$, WTR/ ATR astigmatism $\left(\mathrm{C}_{2}^{2}\right)$ and oblique astigmatism $\left(\mathrm{C}_{2}^{-2}\right)$, and $r$ is the pupil radius.

Statistical nonparametric sign test ${ }^{31}$ and linear mixedmodel analysis were performed to evaluate the changes in refractive error and amount of peripheral retinal image blur between different refractive error groups. Repeated measures analysis of variance was used to analyze refraction changes across the four meridians. A critical $p$-value of 0.05 was used to denote statistical significance. Least-square fitting of the data was applied to minimize the sum of squared residuals and the best fit was determined. A triangle-based cubic interpolation method to fit the IQ data across the $60^{\circ}$ entire visual field was applied in this study to evaluate the IQ in different sections of the visual field.

\section{Results}

Table 1 gives a summary of the participants' age and their central refractive error profiles. Table 2 gives a summary of the major findings of different refraction components $\left(\mathrm{M}, \mathrm{J}_{0}\right.$ and $\mathrm{J}_{45}$ ) with respect to change as a function of visual field eccentricities across the four meridians.

\section{Horizontal visual field}

In order to show clearly the relative changes of $\mathrm{M}$ component at various visual angles, we normalized all the data displayed in Figure 2A by subtracting the central $\mathrm{M}$ value from the measurements at each angle (same in Figures 3A, $4 \mathrm{~A}$ and 5A). Positive and negative values on the $\mathrm{Y}$ axis of Figure $2 \mathrm{~A}$ indicated relative hyperopic and relative myopic shifts, respectively (same in Figures 3A, 4A and 5A). In general, Em. and LM subjects showed small myopic peripheral relative $\mathrm{M}(\mathrm{PRM} ;<1.00 \mathrm{D})$. MM and HM subjects exhibited relative hyperopic shifts (Figure 2A). MM eyes have $2.23 \pm 0.98 \mathrm{D}$ (mean \pm standard error of the mean, same notations in the following text) relative hyperopia in the nasal $30^{\circ}$ visual field, and HM eyes show $2.90 \pm 0.81 \mathrm{D}$ relative hyperopia (Figure 2A). In the temporal visual field, MM and

\begin{tabular}{|c|c|c|c|}
\hline Total subjects $(\mathbf{N}=34)$ & Age (years) & Sphere (D) & Cylinder (D) \\
\hline $\begin{array}{l}\text { Emmetropia }(n=8, \text { from } \\
+0.50 \text { to }-0.50 \mathrm{D})\end{array}$ & $25.56 \pm 7.4 \mathrm{I}$ & $-0.39 \pm 0.15$ & $-1.03 \pm 0.18$ \\
\hline $\begin{array}{l}\text { Low myopia }(n=10, \\
\text { from }-0.75 \text { to }-3.00 \mathrm{D})\end{array}$ & $24.43 \pm 6.54$ & $-1.73 \pm 0.30$ & $-0.76 \pm 0.47$ \\
\hline $\begin{array}{l}\text { Mid myopia }(n=9, \text { from } \\
-3.25 \text { to }-6.00 D)\end{array}$ & $24.28 \pm 5.23$ & $-5.01 \pm 0.29$ & $-1.30 \pm 0.43$ \\
\hline High myopia $(n=7,>-6.00 \mathrm{D})$ & $25.17 \pm 6.02$ & $-7.34 \pm 0.35$ & $-0.85 \pm 0.24$ \\
\hline
\end{tabular}
$\mathrm{HM}$ eyes have $1.10 \pm 0.35$ and $1.39 \pm 0.59 \mathrm{D}$ relative hyperopia,

Table I Study participant's group profiles

Note: Data are expressed as mean \pm SD. 
Table 2 Summary of refraction profiles along four meridians

\begin{tabular}{|c|c|c|c|}
\hline Meridian & M & $J_{0}$ & $J_{45}$ \\
\hline Horizontal & $\begin{array}{l}\text { Em. and LM: myopic PRM }\left(0.70 \mathrm{D} @ 30^{\circ} \text { nasal); MM }\right. \\
\text { and HM: hyperopic PRM, nasal VF exhibits more shift* } \\
\left(\mathrm{HM}, 3.00 \mathrm{D} @ 30^{\circ} \text { nasal; MM, } 2.30 \mathrm{D} @ 30^{\circ} \text { nasal) }\right.\end{array}$ & $\begin{array}{l}\text { Quadratic, increased ATR, nasal } \\
\text { VF exhibits more shift*, maximum } \\
\text { change is } \sim 1.50 \mathrm{D}\left(\mathrm{HM} @ 30^{\circ} \text { nasal) }\right.\end{array}$ & $\begin{array}{l}\text { Linear, negative slope, variation } \\
\text { within } 0.50 \mathrm{D}\end{array}$ \\
\hline $45^{\circ}$ Diagonal & $\begin{array}{l}\text { Em. and LM: flat PRM, no significant shift; MM and HM: } \\
\text { hyperopic PRM, inf. nasal VF exhibits more shift* } \\
\left.\text { (HM, } 4.00 \text { D @ } 30^{\circ} \text { IN; MM, } \sim 3.00 \text { D @ } 30^{\circ} \mathrm{IN}\right)\end{array}$ & $\begin{array}{l}\text { Linear, positive slope, variation } \\
\text { mostly within I.00 D }\end{array}$ & $\begin{array}{l}\text { Quadratic, inf. nasal VF exhibits } \\
\text { more shift*, variation within I.00 D }\end{array}$ \\
\hline Vertical & $\begin{array}{l}\text { Em.: myopic PRM ( } \sim 1.00 \mathrm{D} @ 30^{\circ} \text { superior); LM: } \\
\text { flat PRM, no significant shift; MM and HM: hyperopic } \\
\text { PRM, infer. VF exhibits more shift (HM, } 2.00 \text { D @ } \\
30^{\circ} \text { infer.; MM, } \sim 1.00 \text { D @ } 30^{\circ} \text { infer.) }\end{array}$ & $\begin{array}{l}\text { Quadratic, increased WTR, } \\
\text { variation mostly within I.00 D }\end{array}$ & $\begin{array}{l}\text { Linear, positive slope, variation } \\
\text { mostly within I.00 D }\end{array}$ \\
\hline $135^{\circ}$ Diagonal & $\begin{array}{l}\text { Em. and LM: flat PRM, no significant shift; MM and HM: } \\
\text { hyperopic PRM, super. nasal VF exhibits more shift } \\
\text { (HM, } \sim 4.00 \text { D @ } 30^{\circ} \text { SN; MM, I.40 D @ } 30^{\circ} \text { SN) }\end{array}$ & $\begin{array}{l}\text { Linear, flat slope, variation mostly } \\
\text { within } 0.50 \mathrm{D}\end{array}$ & $\begin{array}{l}\text { Quadratic, super. nasal VF exhibits } \\
\text { more shift*, average } \sim 1.00 \mathrm{D} \\
\text { shift @ } 30^{\circ} \mathrm{SN}\end{array}$ \\
\hline
\end{tabular}

Note: *Indicates statistically significant difference $(p<0.05)$.

Abbreviations: ATR, against the rule; Em, emmetropic; HM, high myopic; IN, inferior nasal; LM, low myopic; MM, moderate myopic; PRM, peripheral relative M; $\mathrm{SN}$, superior nasal; WTR, with the rule; VF, visual field.

respectively, at $30^{\circ}$. Our findings are consistent with previous studies regarding the asymmetry of the spherical power vector component $\mathrm{M}$ in the nasal and temporal horizontal periphery: ${ }^{32-35} \mathrm{MM}$ and HM eyes have more hyperopic shift in the nasal than in the temporal peripheral visual field, with an average of $1.3 \mathrm{D}$ difference when compared for a $30^{\circ}$ angle (Figure 2A). We found greater intersubject variation in HM eyes than in the other group across all visual field angles. The peripheral relative hyperopic shift is statistically significantly different from the PRM shift in the following comparisons between the two groups at $30^{\circ}$ in the temporal visual field and beyond $10^{\circ}$ in the nasal visual field: $\mathrm{HM}$ vs $\operatorname{LM}(F=302.46, p=0.0082), \mathrm{HM}$ vs Em. $(F=173.82, p=0.016)$, $\operatorname{MM}$ vs $\operatorname{LM}(F=128.31, p=0.008)$ and MM vs Em. $(F=187.77$, $p=0.011$ ).

The astigmatic power vector $\mathrm{J}_{0}$ showed quadratic changes across the horizontal visual field (Figure 2B). With an increasing visual field angle, we observed an increased negative $\mathrm{J}_{0}$, which indicated more ATR astigmatism toward the horizontal periphery. The central $\mathrm{J}_{0}$ component in different groups was in the range from $-0.23 \pm 0.68$ to $+0.33 \pm 0.58 \mathrm{D}$. It increased to an average of $-1.21 \pm 0.45$ and $-0.78 \pm 0.51 \mathrm{D}$ at $30^{\circ}$ in the nasal and temporal horizontal fields, respectively. Although the Em. eyes have the least relative ATR increase and the HM eyes have the most relative ATR increase from the center to the horizontal periphery, the differences are not statistically significant $(F=3.14, p=0.16)$. We also identified a nasal-temporal asymmetry in the $\mathrm{J}_{0}$ profiles as follows: more ATR astigmatism was observed in the nasal visual field than in the temporal visual field ( $F=101.52, p=0.0002$, $0.42 \mathrm{D}$ difference at $30^{\circ}$ visual field angle). There was higher intersubjective variation in the periphery $(0.87 \pm 0.21 \mathrm{D})$ than in the center $(0.35 \pm 0.08 \mathrm{D}$; Figure $2 \mathrm{~B})$.
The astigmatic power vector $\mathrm{J}_{45}$ was found, using leastsquare fitting, to be related linearly to the horizontal field angles, and it showed a maximum change of $<0.5 \mathrm{D}$ across the visual field. The change of $\mathrm{J}_{45}$ as a function of the visual field angle showed negative slopes for all groups. There were no significant differences between the slopes of any two groups (all $p>0.05$ ), and these slopes were not significantly different from zero. The slope values varied from $-0.002 \mathrm{D} /$ degree (D/Deg.) in moderate myope group to $-0.01 \mathrm{D} / \mathrm{Deg}$. in low myope group (Figure 2C).

\section{$45^{\circ}$ Diagonal visual field}

Consistent with the findings of the PRM profiles for MM and HM subjects across the horizontal meridian, PRM also showed a hyperopic shift across the $45^{\circ}$ diagonal visual field in these two subject groups. High myopes had more hyperopic shift in the periphery than moderate myopes (Figure 3A). There were significantly larger hyperopic shift in high myopes than in moderate myopes at the inferior nasal (IN) $20^{\circ}$ and $30^{\circ}(F=181.27, p=0.003)$. In addition, an asymmetric profile was also observed with larger amounts of hyperopic PRM shift in the IN visual field than in the superior temporal (ST) visual field. High myopes exhibited $4.16 \pm 0.53 \mathrm{D}$ hyperopic shift at the $30^{\circ} \mathrm{IN}$ visual field and $2.70 \pm 0.60 \mathrm{D}$ hyperopic shift at the $30^{\circ} \mathrm{ST}$ visual field, with $1.46 \mathrm{D}$ difference between IN and ST visual fields. Moderate myopes showed $2.92 \pm 0.95$ and $1.91 \pm 1.07 \mathrm{D}$ hyperopic shifts at the $30^{\circ} \mathrm{IN}$ and ST, respectively, with $1.00 \mathrm{D}$ difference (Figure 3A).

Unlike the myopic shift profiles of PRM in low myopes and emmetropes across the horizontal visual field, the changes of PRM in these two groups showed flat profiles across the $45^{\circ}$ diagonal visual field with a variation of $<1.0 \mathrm{D}$ in Em. 

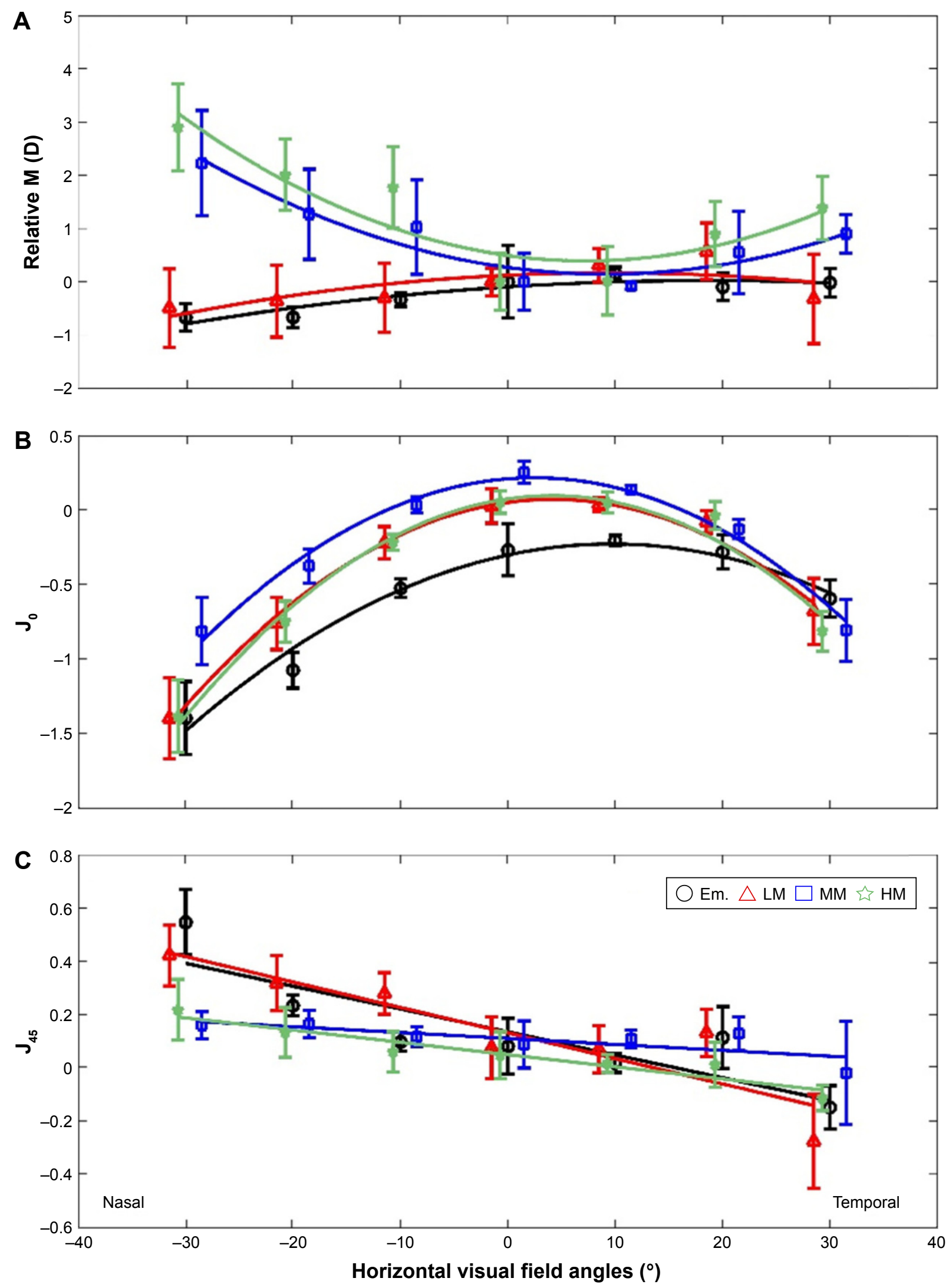

Figure 2 Changes of refractive components as functions of horizontal visual field angle.

Notes: (A) The $Y$ axis shows the mean relative $M$, which is equal to (peripheral $M$ - on-axis $M$ ). (B) The $Y$ axis shows mean $J_{0}$. (C) The $Y$ axis shows mean $J_{45^{\circ}}$ Least-square fitting was made to fit curves and lines to better show the profiles across the visual fields of each refractive component. Error bars show the SEM for each group. For clarity, symbols and error bars are staggered slightly horizontally.

Abbreviations: Em., emmetropic; HM, high myopic; LM, low myopic; MM, moderate myopic; SEM, standard error of the mean. 

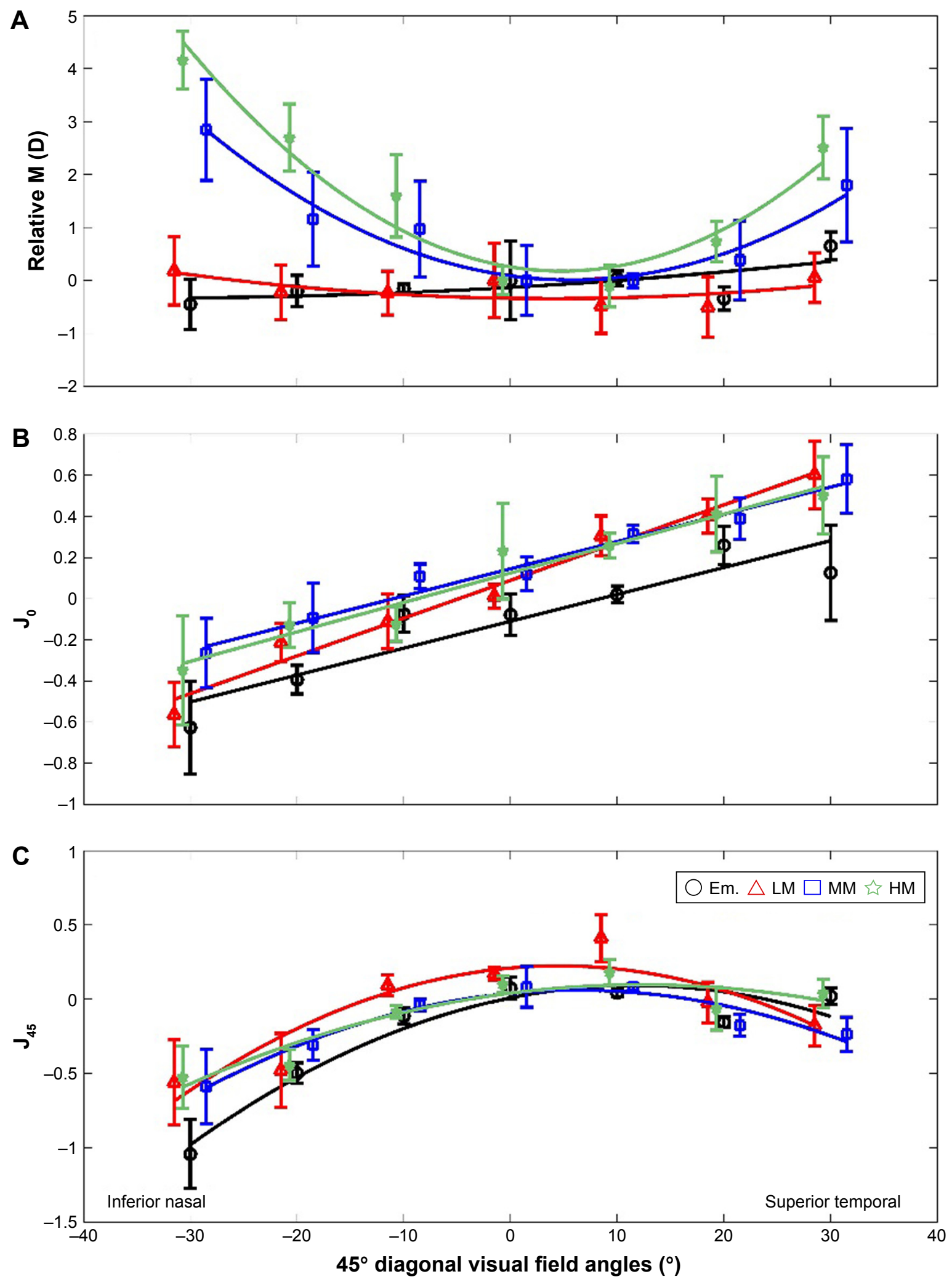

Figure 3 Changes of refractive components as functions of $45^{\circ}$ diagonal visual field eccentricities.

Notes: (A) The $Y$ axis shows mean relative M. (B) The $Y$ axis shows mean $J_{0}$. (C) The $Y$ axis shows mean $J_{45^{5}}$ Error bars show the SEM for each group. For clarity, symbols and error bars are staggered slightly horizontally.

Abbreviations: Em., emmetropic; HM, high myopic; LM, low myopic; MM, moderate myopic; SEM, standard error of the mean. 

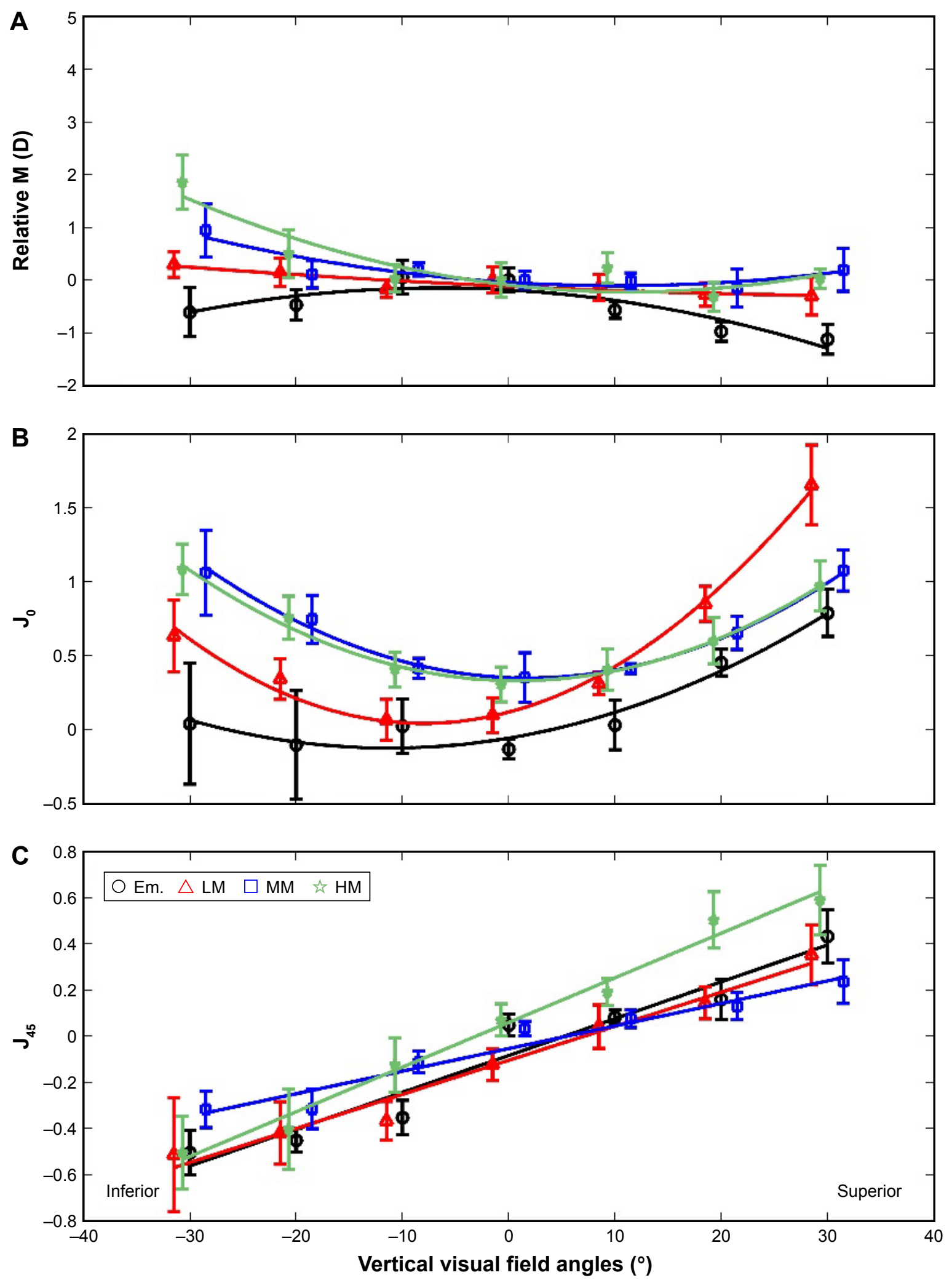

Figure 4 Changes of refractive components as functions of vertical visual field eccentricities.

Notes: (A) The $Y$ axis shows mean relative M. (B) The $Y$ shows mean $J_{0}$. (C) The $Y$ axis shows mean $\int_{45}$. Error bars show the SEM for each group. For clarity, symbols and error bars are staggered slightly horizontally.

Abbreviations: Em., emmetropic; HM, high myopic; LM, low myopic; MM, moderate myopic; SEM, standard error of the mean. 

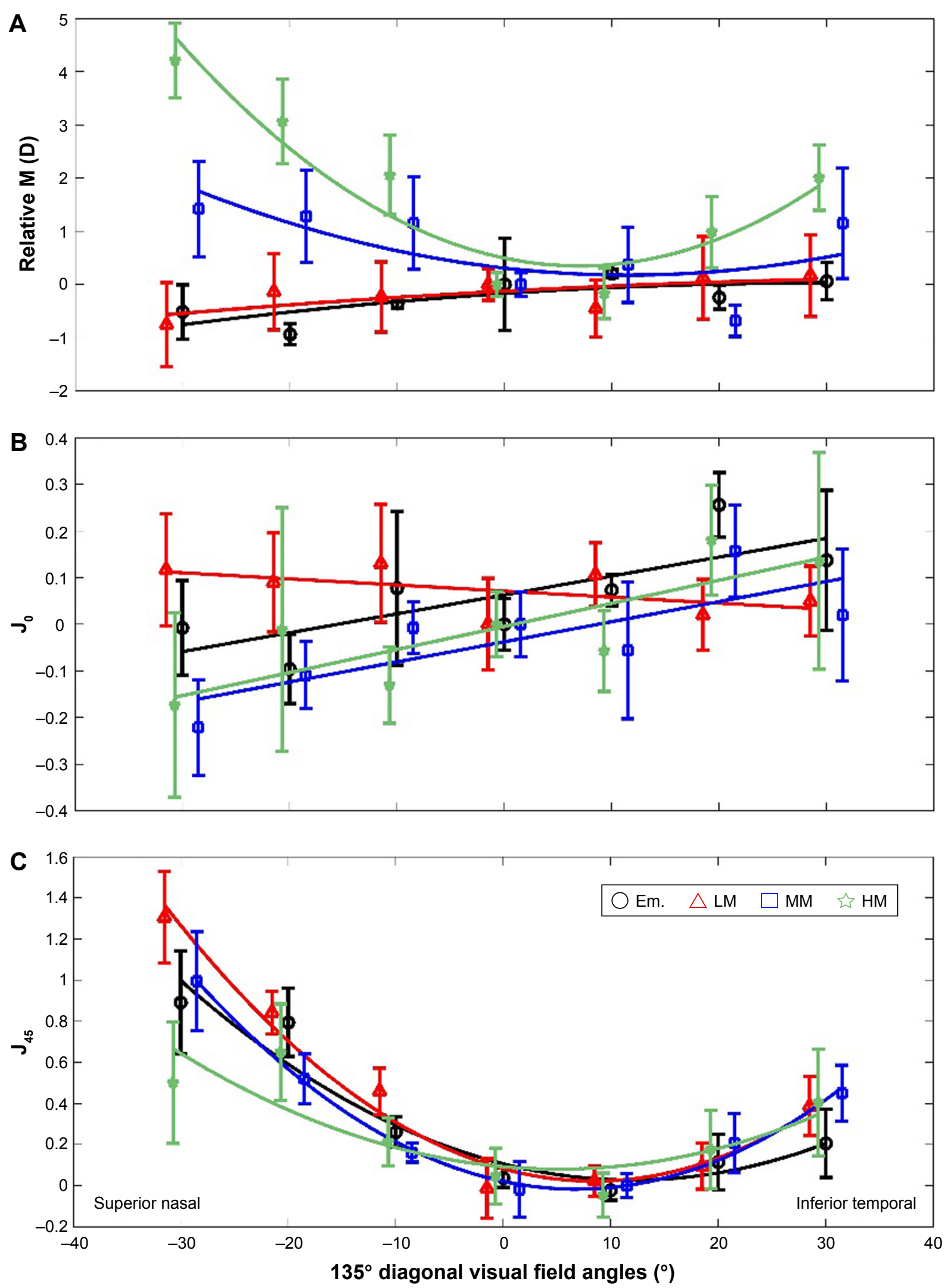

Figure 5 Changes of refractive components as functions of $135^{\circ}$ diagonal visual field eccentricities.

Notes: (A) The $Y$ axis shows mean relative M. (B) The $Y$ axis shows mean $J_{0}$. (C) The $Y$ axis shows mean $J_{45}$. Error bars show the SEM for each group. For clarity, symbols and error bars are staggered slightly horizontally.

Abbreviations: Em., emmetropic; HM, high myopic; LM, low myopic; MM, moderate myopic; SEM, standard error of the mean. 
and 0.60 D in LM subject groups. There were no significant differences of PRM at any visual field angle between the two groups $(F=0.52, p=0.752$; Figure $3 \mathrm{~A})$.

$\mathrm{J}_{0}$ showed a linear function across the $45^{\circ}$ diagonal visual field from the IN to the ST quadrant with positive slopes in all groups. Increased ATR astigmatisms were observed toward the IN visual field. In contrast, increased WTR astigmatisms were found toward the ST visual field. There were no significant differences in the slopes of the linear $\mathrm{J}_{0}$ variation profiles between the four groups $(F=21.06, p=0.855)$. They had an average slope value of $0.015 \pm 0.006 \mathrm{D} / \mathrm{Deg}$. The changes of $\mathrm{J}_{0}$ were within $1.00 \mathrm{D}$ across the entire $60^{\circ}$ visual field except for the LM group, which had a $\mathrm{J}_{0}$ variation of $1.30 \mathrm{D}(-0.60 \mathrm{D}$ at the IN $30^{\circ}$ and $0.70 \mathrm{D}$ at the ST $30^{\circ}$; Figure $3 \mathrm{~B}$ ).

The power vector component $\mathrm{J}_{45}$ exhibited a quadratic change with visual field eccentricities across the $45^{\circ}$ diagonal meridian for all four subjects groups. More negative values of $\mathrm{J}_{45}$ were found in the IN and the ST visual fields than in the central $\mathrm{J}_{45}$. Although the groups showed slightly different patterns, there were no significant differences of the $\mathrm{J}_{45}$ profile $(F=4.76, p=0.16$; Figure $3 \mathrm{C})$. IN-ST asymmetry existed in $\mathrm{J}_{45}$ profiles with more negative values of $\mathrm{J}_{45}$ in the IN visual field $\left(-0.87 \pm 0.16 \mathrm{D}\right.$ at $\left.30^{\circ} \mathrm{IN}\right)$ than in the ST visual field $\left(-0.21 \pm 0.087 \mathrm{D}\right.$ at $\left.30^{\circ} \mathrm{ST}\right)$. Greater between-subjects variation occurred at larger off-axis eccentricities (Figure 3C).

\section{Vertical visual field}

Myopic PRM was observed in the Em. group across the vertical visual field, while moderate and high myopes tended to have hyperopic peripheries (Figure 4A). This was consistent with the findings of PRM profiles in the horizontal and $45^{\circ}$ diagonal meridians. PRM varied in a small range of $0.50 \mathrm{D}$ for the low myopes. LM subjects tended to have a hyperopic shift in the inferior visual field (Figure 4A, blue symbols). When comparing the amount of hyperopic shift of PRM in MM and HM subjects, more hyperopic shift was found in high myopes $(F=172.43, p=0.0045)$. There was a $1.94 \pm 0.87 \mathrm{D}$ hyperopic shift of PRM in the inferior $30^{\circ}$ visual field in HM group. This was 1.0 D larger than that in the MM group (Figure 4A). The asymmetry of PRM profiles in the inferior and superior visual fields was also noticeable. There were more hyperopic shifts toward the inferior visual field than toward the superior visual field in the MM and HM groups, and there were more myopic shifts toward the superior quadrant than toward the inferior field for the Em. group. The Em. subjects had $-1.32 \pm 0.65 \mathrm{D}$ myopic shift in the superior visual field and $-0.64 \pm 0.41 \mathrm{D}$ myopic shift in the inferior visual field. Larger amounts of between-subjects variations were also present with increasing visual field eccentricities $\left(0.52 \pm 0.32 \mathrm{D}\right.$ at $30^{\circ}$ inferior vs $0.23 \pm 0.17 \mathrm{D}$ at the center; Figure 4A).

$\mathrm{J}_{0}$ across the vertical meridian also exhibited a quadratic function with an increase in off-axis angles (Figure 4B). But unlike the $\mathrm{J}_{0}$ changes across the horizontal meridian, WTR astigmatisms were found toward the vertical periphery. The variation of $\mathrm{J}_{0}$ across the visual field was within the range of $1.00 \mathrm{D}$ for all subject groups except for the LM group, which showed an increase of $1.80 \pm 0.76 \mathrm{D}$ WTR astigmatism in the superior visual field toward $30^{\circ}$ periphery. The asymmetry of the $\mathrm{J}_{0}$ profile in the two quadrants was more noticeable in the Em. and LM groups. More WTR astigmatism appeared in the superior visual field than in inferior visual field $\left(30^{\circ}\right.$ : $F=76.38, p=0.002$; Figure 4B).

$\mathrm{J}_{45}$ showed a linear relationship with the change in vertical visual field angles (Figure 4C). Positive slopes were found, with an average value of $0.02 \pm 0.008 \mathrm{D} / \mathrm{Deg}$, regardless of the foveal refractions. There were no significant differences in the slopes. From inferior $30^{\circ}$ to superior $30^{\circ}, \mathrm{J}_{45}$ changed $1.15 \mathrm{D}$ in the HM group, while the change was $0.87 \pm 0.07 \mathrm{D}$ for all the other groups (Figure 4C).

\section{$135^{\circ}$ Diagonal visual field}

PRM showed hyperopic shifts in the periphery of the $135^{\circ}$ visual field for MM and HM subjects ( $F=103.34, p=0.0072$; Figure 5A). HM subjects exhibited more hyperopic shifts than MM subjects $(F=32.78, p=0.017)$. In the superior nasal (SN) quadrant, PRM shifted to $4.12 \pm 0.71$ and $1.41 \pm 0.62 \mathrm{D}$ for high and moderate myopes, respectively. In the inferior temporal (IT) quadrant, the hyperopic shifts were $2.03 \pm 0.31$ and 1.17 $\pm 0.49 \mathrm{D}$ for these two groups, respectively. This also indicated an SN-IT asymmetry of the PRM profiles for the two groups: moderate to high myopes tended to have more hyperopic shifts in the $\mathrm{SN}$ visual field. There were no noticeable myopic or hyperopic shifts to the periphery across this meridian in Em. and LM subjects $(F=5.07, p=0.321)$. But these groups tended to exhibit slight myopic shifts in the superior visual fields. The PRM values varied in a range of $0.70 \mathrm{D}$ for these two groups across the entire $60^{\circ}$ oblique visual field (Figure 5A).

$\mathrm{J}_{0}$ exhibited a linear dependence of the visual field angles across the $135^{\circ}$ diagonal meridian for all subject groups (Figure 5B). Except the LM group, all groups demonstrated a positive slope, although it was relatively flat (slope value $=0.006 \pm 0.001 \mathrm{D} / \mathrm{Deg}$.). From the $\mathrm{SN}$ to the IT visual 
field, $\mathrm{J}_{0}$ astigmatism varied in a small range of $0.50 \mathrm{D}$ in the study groups. There were increases in the between-subjects measurement variances (Figure 5B). The $\mathrm{J}_{45}$ astigmatism component showed a quadratic relationship with the increase in visual field angle toward the $\mathrm{SN}$ and the IT peripheries (Figure 5C). However, there were no statistical differences of these quadratic patterns between the different study groups $(F=54.69, p=0.23)$. A noticeable SN-IT asymmetry in the $\mathrm{J}_{45}$ shift was found, and there were larger amounts of $\mathrm{J}_{45}$ in the SN quadrant than in the IT quadrant (on an average of $0.97 \pm 0.63$ and $0.36 \pm 0.25 \mathrm{D}$ at the $30^{\circ} \mathrm{SN}$ and IT periphery, respectively). Increased between-subjects variances were also observed when the measurements were taken at larger off-axis angles (Figure 5).

\section{Peripheral IQ}

The results described above show that the spherical component $\mathrm{M}$ and the astigmatic power vectors vary across the entire visual field. If IQ is a driving force for myopia progression as suggested previously, ${ }^{4-8}$ it is important to determine the combined effects of $\mathrm{M}, \mathrm{J}_{0}$ and $\mathrm{J}_{45}$. To determine the peripheral IQ which combines the optical effects of spherical and astigmatic power vector components, we analyzed the total sphero-cylindrical image blur on the peripheral retina across the entire visual field. We calculated this total Sphero-Cylindrical Retinal Image Blur (SCRIB) using the following equation:

$$
\mathrm{SCRIB}=\sqrt{\mathrm{M}^{2}+\mathrm{J}_{0}^{2}+\mathrm{J}_{45}^{2}}
$$

We use a triangle-based cubic interpolation method ${ }^{21}$ to fit the SCRIB data across the $60^{\circ}$ entire visual field. Em. eyes show an increased amount of SCRIB in all peripheral eccentricities (all $p<0.05$ ) with exceptions of far periphery $\left(30^{\circ}\right)$ at the IT and ST visual fields (both $p>0.05$ ). The greatest SCRIB increase, $1.38 \pm 0.71 \mathrm{D}$, was found at $30^{\circ}$ nasal periphery (Figure 6A). All myopia groups show increased image blur in the nasal, superior nasal and superior visual fields (all $p<0.05$ ), but with much lower amount (about 1/2) compared with emmetropes (Figure 6B-D). The SCRIB decrease in T, IT, and I visual field (VF) of myopic subjects. A nearly one-third diopter smaller retinal image blur was noticed at $30^{\circ}$ in IT
A
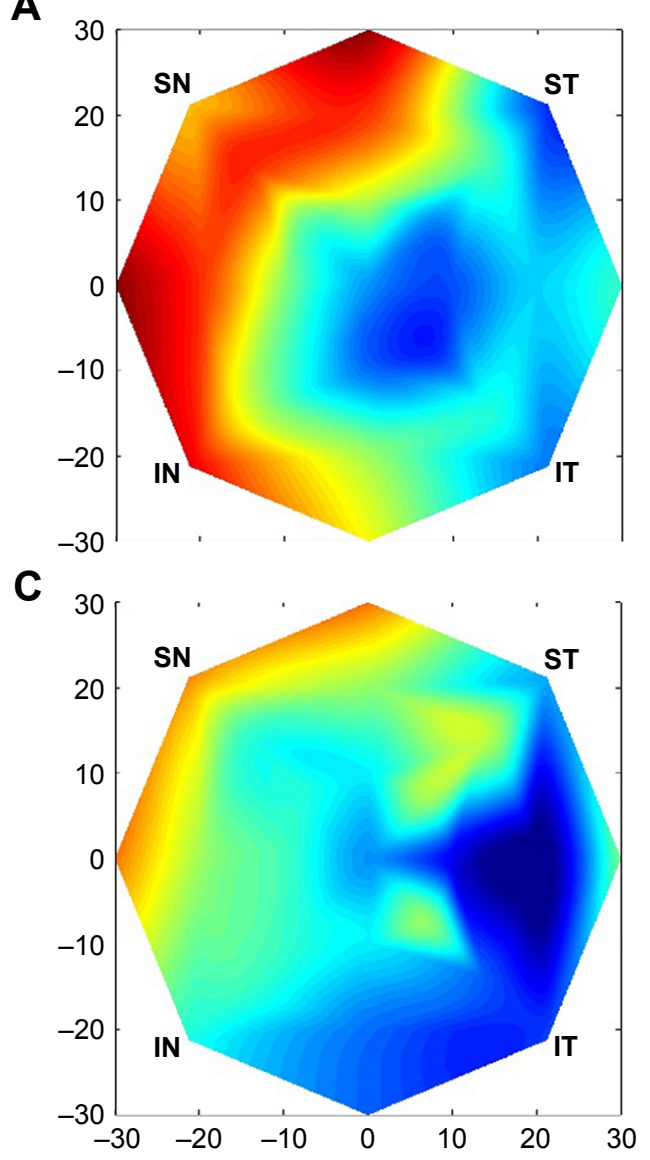

B

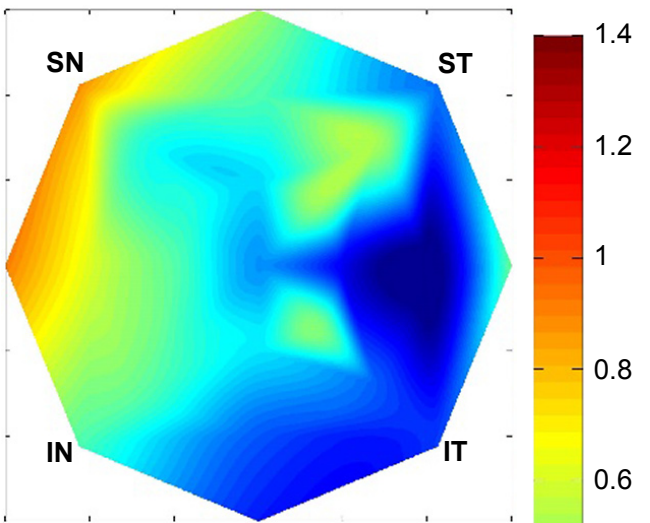

D .

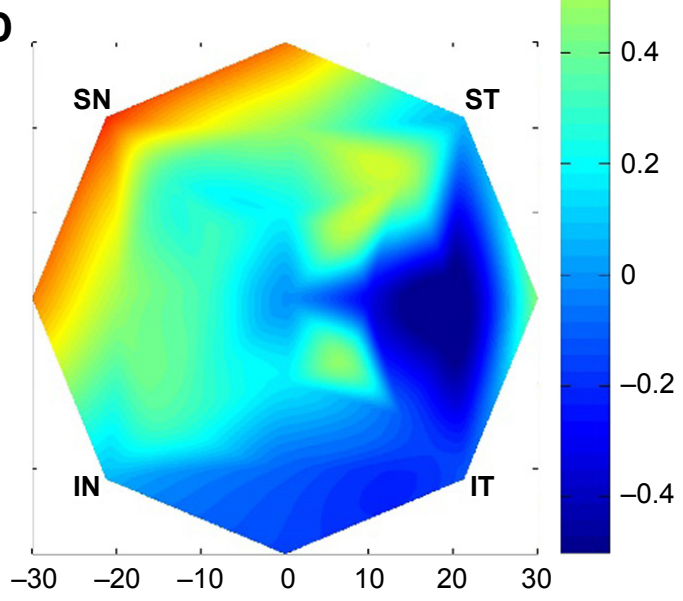

Figure 6 Relative SCRIB data (peripheral SCRIB - central SCRIB) fitted across $60^{\circ}$ visual field using a triangle-based cubic interpolation method in (A) emmetropia, (B) low myopia, (C) moderate myopia and (D) high myopia.

Abbreviations: IN, inferior nasal; IT, inferior temporal; SCRIB, Sphero-Cylindrical Retinal Image Blur; SN, superior nasal; ST, superior temporal. 
visual field compared with the center. The best IQ, in terms of SCRIB, was achieved between $10^{\circ}$ and $20^{\circ}$ in the temporal visual field of myopic subjects (Figure 6B-D).

\section{Discussion}

Most of the previous studies on peripheral optics of the human eye were conducted only along the horizontal and vertical visual fields. ${ }^{29,33,36-40}$ These studies show that the refraction varies differently along the nasal and temporal visual fields. Our study confirmed that a myopic eye along the horizontal visual field is generally less myopic (or relatively hyperopic) in its periphery. As pointed out in previous studies, ${ }^{29,40}$ the magnitude of spherical power vector component $\mathrm{M}$ varies in proportion to the foveal refractive error. We found in our study that, along the horizontal meridian, moderate and high myopes showed higher amounts of relative hyperopic refractive error compared to low myopes and emmetropes. As expected, the astigmatism (mainly the $\mathrm{J}_{0}$ component) increased dramatically (quadratically as a function of the visual field angle) and exhibited more ATR astigmatism into the horizontal periphery. This would deteriorate the peripheral retinal IQ considerably.

Our finding suggests that the conventional approach to generalize the characteristics of peripheral refraction and retinal IQ solely based on findings in the horizontal visual field is questionable since the real eyes do not generally exhibit rotational symmetry. ${ }^{41,42}$ The few existing studies which extended peripheral refraction measurements to other peripheral positions in addition to horizontal meridian found different amounts of peripheral refractive errors for other meridians. ${ }^{34,39,43,44}$ For example, Seidemann et a ${ }^{39}$ conducted photorefraction measurements across $22^{\circ}$ of the visual field of 18 myopic subjects. Their results show relative peripheral myopia across the retina, except for the superior visual field in which they found relative hyperopia. Mathur et al, ${ }^{43}$ using aberrometry in nine myopia subjects, found relative peripheral myopia across the retina in all their subjects. Atchison et $\mathrm{al},{ }^{32}$ by performing autorefraction measurements along both horizontal and vertical meridians, found that myopic eyes showed relative hyperopia along the horizontal meridian but relative myopia along the vertical meridian. Consistent with Atchison et al, Berntsen et $\mathrm{al}^{44}$ reported myopic children have relative hyperopia in horizontal periphery and relative myopia in vertical periphery. A cross-sectional study conducted by Ehsaei et al reported that myopic eyes show a relative hyperopic shift in the periphery along all four measured meridians. ${ }^{34}$

The conflicting findings in these studies may, partly, be caused by the variation of subjects' myopia severity from study to study. We found that MM and HM subjects have relative hyperopic periphery in all four meridians. The data reveal that a higher amount of central myopia is associated with more peripheral relative hyperopic shift. Figure 7 gives an illustration of the differences in PRM patterns of the four groups in this study. Em. eyes exhibited a relative myopic shift in five out of eight octants. LM eyes exhibited an LM shift in three out of eight octants and a hyperopic shift in one octant. All the other octants in these two subject groups showed close to zero PRM, which means no relative hyperopic or myopic defocus shift. In contrast, MM to HM eyes did not exhibit any myopic PRM patterns. All eight octants in these two subject groups showed a hyperopic shift. The amount of this hyperopic shift increased with the amount of their central myopia.

It is readily observed that patterns of PRM are associated with the refractive states of central vision (Figure 7). Although previous studies have suggested that PRM may influence the development of a central refractive error, ${ }^{4-8,12-15}$ the causal-effect relationship remains undetermined. This means that it is still unclear whether hyperopic PRM is a driving force for the refractive error development or is simply a result of the myopia progression. ${ }^{29,45}$ A recent study, using three-dimensional magnetic resonance imaging to investigate the changes in eye dimensions and retinal shape with the degree of myopia, suggested that eyes' oblateness decreased with an increase in myopia. ${ }^{41}$ Our results confirm that, as myopia increases, more hyperopic PRM is found across the entire visual field in all meridians. Therefore, the shape of the retina is relatively more prolate, or less oblate, in moderate and high myopes. Data in this study also suggest that emmetropes and low myopes, in contrast, tend to have an overall spherical or some degree of oblate retinal shapes. These findings are in agreement with the results from another cross-sectional study of peripheral refraction in myopes and emmetropes. ${ }^{34}$ An overall larger amount of image blur in the periphery of Em. eyes in this study may indicate the causation of myopia onset and progression based "grow to clarity" theory. ${ }^{16}$

Off-axis astigmatism increased considerably with visual field eccentricities. ${ }^{29}$ Although a number of animal studies using chicken model suggested that imposed astigmatic error does not play an important role during emmetropization, ${ }^{46,47}$ some other studies showed that astigmatism could influence the development of myopia ${ }^{48,49}$ or emmetropization process. ${ }^{5}$ Thus, it is still unclear whether off-axis astigmatism influences refractive error development. Our findings of quadratic field dependence of the $\mathrm{J}_{0}$ to horizontal and vertical eccentricities, and those of quadratic field dependence of the 

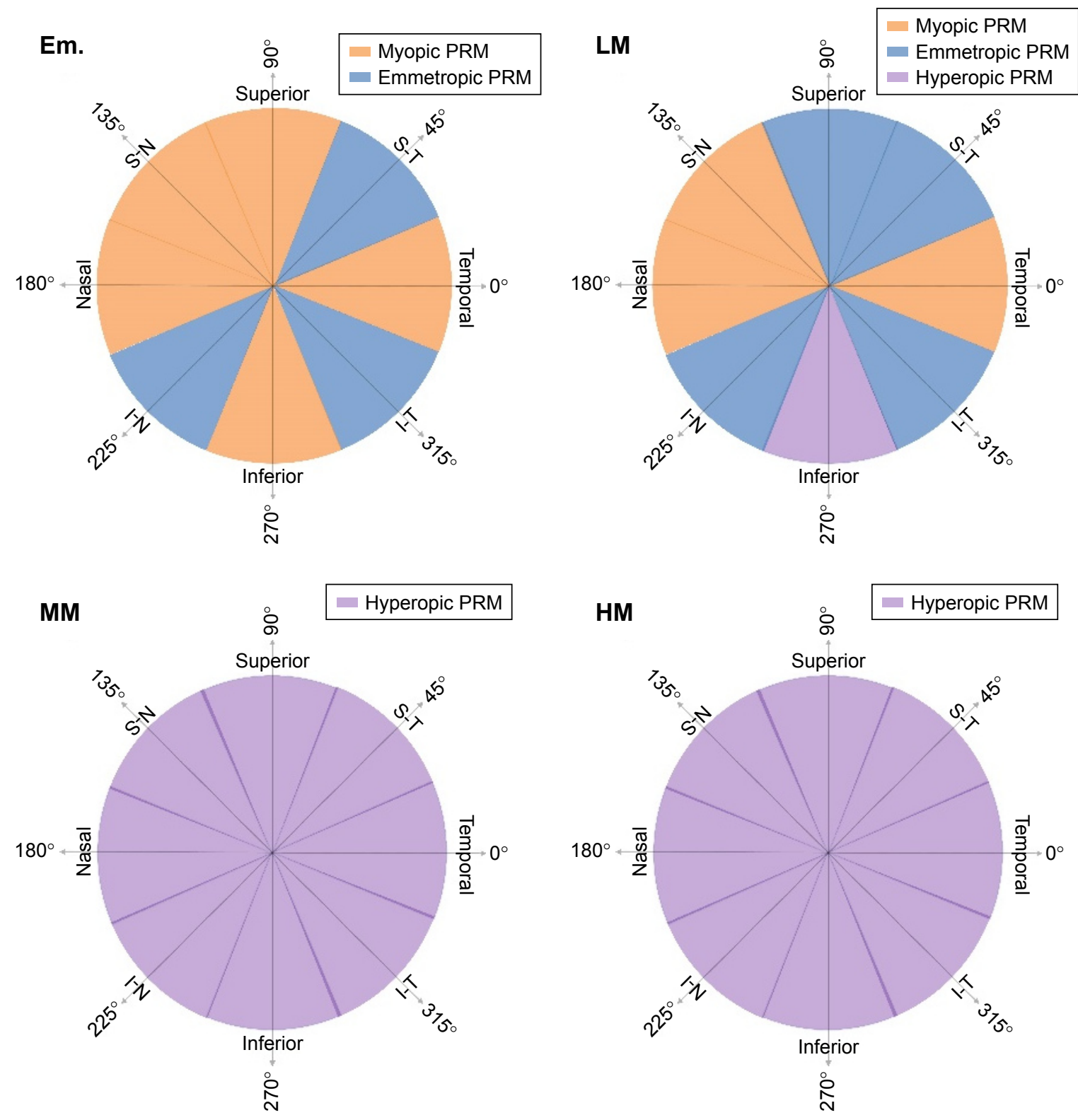

Figure 7 PRM patterns in different subject groups.

Note: Color patterns are only for illustration purpose to distinguish myopic, hyperopic or emmetropic PRM and not to represent the actual data.

Abbreviations: Em., emmetropic; HM, high myopic; LM, low myopic; MM, moderate myopic; PRM, peripheral relative M.

$\mathrm{J}_{45}$ to $45^{\circ}$ and $135^{\circ}$ diagonal visual field eccentricities are consistent with Seidel's theory..$^{50}$ According to this theory, the M component (defocus) of the refraction shows quadratic field dependence. This was also apparent in our data, especially for MM to HM subjects, across all the four meridians in the entire visual field.

\section{Conclusion}

This study examined the peripheral refractive error changes in all four major meridians of the human eye with detailed subgrouping based on the amount of their central myopic refractive error. The findings indicate an overall Em. or slightly relative myopic periphery (spherical or oblate retinal shape) formed in emmetropes and low myopes, while moderate and high myopes form relative hyperopic periphery (prolate, or less oblate, retinal shape). In general, human Em. eyes demonstrate higher amount of peripheral retinal image blur.

\section{Disclosure}

The authors report no conflicts of interest in this work.

\section{References}

1. Fankhauser F, Enoch JM. The effects of blur upon perimetric thresholds. A method for determining a quantitative estimate of retinal contour. Arch Ophthalmol. 1962;68:240-251. 
2. Wang YZ, Thibos LN. Oblique (off-axis) astigmatism of the reduced schematic eye with elliptical refracting surface. Optom Vis Sci. 1997; 74(7):557-562.

3. Williams DR, Artal P, Navarro R, McMahon MJ, Brainard DH. Offaxis optical quality and retinal sampling in the human eye. Vision Res. 1996;36:1103-1114.

4. Charman WN. Aberrations and myopia. Ophthalmic Physiol Opt. $2005 ; 25(4): 285-301$

5. Kee CS, Hung LF, Qiao-Grider Y, Roorda A, Smith EL 3rd. Effects of optically imposed astigmatism on emmetropization in infant monkeys. Invest Ophthalmol Vis Sci. 2004;45(6):1647-1659.

6. Marcos S, Barbero S, Llorente L. The sources of optical aberrations in myopic eyes. Invest Ophthalmol Vis Sci. 2002;43(13):Abstract 1510.

7. Thorn F, He J, Thom S, Held R, Gwiazda J. The vision of myopic children: how wavefront aberrations alter the image of school book text. Myopia 2000: Proceedings of the VIII International Conference in Myopia. Boston; 2000.

8. Wildsoet C. Structural correlates of myopia. In: Rosenfield M, Gilmartin B, editors. Myopia and Nearwork. New York, NY: Butterworth-Heinemann; 1998:31-56.

9. Wallman J, Winawer J. Homeostasis of eye growth and the question of myopia. Neuron. 2004;43:447-468.

10. Hodos W, Kuenzel WJ. Retinal-image degradation produces ocular enlargement in chicks. Invest Ophthalmol Vis Sci. 1984;25(6): 652-659.

11. Diether S, Schaeffel F. Local changes in eye growth induced by imposed local refractive error despite active accommodation. Vision Res. 1997;37(6):659-668

12. Schmid GF. Retinal steepness vs myopic shift in children (Abstract). Optom Vis Sci. 2004;12:23.

13. Walline J, Jones LA, Mutti DO, Zadnik K. A randomized trial of the effects of rigid contact lenses on myopia progression. Arch Ophthalmol. 2004;122(12):1760-1766.

14. Hoogerheide J, Rempt F, Hoogenboom WP. Acquired myopia in young pilots. Ophthalmologica. 1971;163(4):209-215.

15. Mutti DO, Sholtz RI, Friedman NE, Zadnik K. Peripheral refraction and ocular shape in children. Invest Ophthalmol Vis Sci. 2000;41(5): 1022-1030.

16. Wildsoet CF. Active emmetropization - evidence for its existence and ramifications for clinical practice. Ophthalmic Physiol Opt. 1997; 17(4):279-290.

17. Wang YZ, Thibos LN, Lopez N, Salmon T, Bradley A. Subjective refraction of the peripheral field using contrast detection acuity. J Am Optom Assoc. 1996;67(10):584-589.

18. Berntsen DA, Mutti DO, Zadnik K. Validation of aberrometry-based relative peripheral refraction measurements. Ophthal Physiol Opt. 2008;28(1):83-90.

19. Radhakrishnan H, Charman WN. Refractive changes associated with oblique viewing and reading in myopes and emmetropes. $J$ Vis 2007;7(8):5.

20. Jaeken B, Artal P. Optical quality of emmetropic and myopic eyes in the periphery measured with high-angular resolution. Invest Ophthalmol Vis Sci. 2012;53(7):3405-3413.

21. Mathur A, Atchison DA, Scott DH. Ocular aberrations in the peripheral visual field. Opt Lett. 2008;33(8):863-865.

22. Osuagwu UL, Suheimat M, Atchison DA. Peripheral aberrations in adult hyperopes, emmetropes and myopes. Ophthalmic Physiol Opt. 2017;37(2):151-159.

23. Collins MJ, Wildsoet CF, Atchison DA. Monochromatic aberrations and myopia. Vision Res. 1995;35(9):1157-1163.

24. Li L, Cheng GPM, Ng ALK, Chan TCY, Jhanji V, Wang Y. Influence of refractive status on the higher-order aberration pattern after small incision lenticule extraction surgery. Cornea. 2017;36(8):967-972.

25. Thibos LN, Hong X. Clinical applications of the Shack-Hartmann aberrometer. Optom Vis Sci. 1999;76(12):817-825.

26. Cheng X, Himebaugh NL, Kollbaum PS, Thibos LN, Bradley A. Validation of a clinical Shack-Hartmann aberrometer. Optom Vis Sci. 2003; 80(8):587-595.
27. Cheng X, Himebaugh NL, Kollbaum PS, Thibos LN, Bradley A. Testretest reliability of clinical Shack-Hartmann measurements. Invest Ophthalmol Vis Sci. 2004;45(1):351-360.

28. Shen J, Thibos LN. Measuring ocular aberrations and image quality in peripheral vision with a clinical wavefront aberrometer. Clin Exp Optom. 2009;92(3):212-222.

29. Shen J, Clark CA, Soni PS, Thibos LN. Peripheral refraction with and without contact lens correction. Optom Vis Sci. 2010;87(9):642-655.

30. Thibos LN, Wheeler W, Horner D. Power vectors: an application of Fourier analysis to the description and statistical analysis of refractive error. Optom Vis Sci. 1997;74(6):367-375.

31. Siegel S. Nonparametric Statistics for the Behavioral Sciences. New York, NY: McGraw-Hill; 1956.

32. Atchison DA, Pritchard N, Schmid KL. Peripheral refraction along the horizontal and vertical visual fields in myopia. Vision Res. 2006; 46(8-9):1450-1458.

33. Atchison DA, Scott DH, Charman WN. Hartmann-Shack technique and refraction across the horizontal visual field. J Opt Soc Am A Opt Image Sci Vis. 2003;20(6):965-973.

34. Ehsaei A, Mallen EA, Chisholm CM, Pacey IE. Cross-sectional sample of peripheral refraction in four meridians in myopes and emmetropes. Invest Ophthalmol Vis Sci. 2011;52(10):7574-7585.

35. Ferree C, Rand G, Hardy C. Refraction for the peripheral field of vision. Arch Ophthalmol. 1931;5:717-731.

36. Lu F, Mao X, Qu J, Xu D, He JC. Monochromatic wavefront aberrations in the human eye with contact lenses. Optom Vis Sci. 2003; 80(2):135-141.

37. Lundstrom L, Unsbo P, Gustafsson J. Off-axis wave front measurements for optical correction in eccentric viewing. J Biomed Opt. 2005; 10(3):034002.

38. Mutti DO, Haves JR, Mitchell GL, et al. Refractive error, axial length, and relative peripheral refractive error before and after the onset of myopia. Invest Ophthalmol Vis Sci. 2007;48(6):2510-2519.

39. Seidemann A, Schaeffel F, Guirao A, Lopez-Gil N, Artal P. Peripheral refractive errors in myopic, emmetropic, and hyperopic young subjects. J Opt Soc Am A Opt Image Sci Vis. 2002;19(12):2363-2373.

40. Atchison DA. Higher order aberrations across the horizontal visual field. J Biomed Opt. 2006;11(3):34026.

41. Pope JM, Verkicharla PK, Sepehrband F, Suheimat M, Schmid KL, Atchison DA. Three-dimensional MRI study of the relationship between eye dimensions, retinal shape and myopia. Biomed Opt Express. 2017; 8(5):2386-2395.

42. Verkicharla PK, Mathur A, Mallen EA, Pope JM, Atchison DA. Eye shape and retinal shape, and their relation to peripheral refraction. Ophthalmic Physiol Opt. 2012;32(3):184-199.

43. Mathur A, Atchison DA, Charman WN. Myopia and peripheral ocular aberrations. J Vis. 2009;9(10):p15.

44. Berntsen DA, Mutti DO, Zadnik K. Study of Theories about Myopia Progression (STAMP) design and baseline data. Optom Vis Sci. 2010; 87(11):823-832.

45. Atchison DA, Rosen R. The possible role of peripheral refraction in development of myopia. Optom Vis Sci. 2016;93(9):1042-1044.

46. McLean RC, Wallman J. Severe astigmatic blur does not interfere with spectacle lens compensation. Invest Ophthalmol Vis Sci. 2003;44(2): $449-457$.

47. Schmid K,Wildsoet CF. Natural and imposed astigmatism and their relation to emmetropization in the chick. Exp Eye Res. 1997;64(5): $837-847$.

48. Fulton AB, Hansen RM, Petersen RA. The relation of myopia and astigmatism in developing eyes. Ophthalmology. 1982;89(4):298-302.

49. Irving EL, Callender MG, Sivak JG. Inducing ametropias in hatchling chicks by defocus-aperture effects and cylindrical lenses. Vision Res. 1995;35(9):1165-1174.

50. Smith G, Atchison DA. The Eye and Visual Optical Instruments. Cambridge: Cambridge University Press; 1997:601. 


\section{Publish your work in this journal}

Clinical Ophthalmology is an international, peer-reviewed journal covering all subspecialties within ophthalmology. Key topics include: Optometry; Visual science; Pharmacology and drug therapy in eye diseases; Basic Sciences; Primary and Secondary eye care; Patient Safety and Quality of Care Improvements. This journal is indexed on

Submit your manuscript here: http://www.dovepress.com/clinical-ophthalmology-journal
PubMed Central and CAS, and is the official journal of The Society of Clinical Ophthalmology (SCO). The manuscript management system is completely online and includes a very quick and fair peer-review system, which is all easy to use. Visit http://www.dovepress.com/ testimonials.php to read real quotes from published authors. 